\title{
Spectrum of Aetiological Agents of Endophthalmitis and Antimicrobial Resistance Pattern of Bacterial Isolates
}

\author{
Sukhjinder Singh, Loveena Oberoi*, Karamjit Singh, \\ Sapna Soneja and Anuradha Malhotra
}

\author{
Department of Microbiology, Government Medical College, Amritsar, Baba Farld University \\ of Health Sciences, Punjab, India \\ *Corresponding author
}

\begin{abstract}
A B S T R A C T
Eye is a complex and sensitive organ and is therefore more vulnerable to trauma and various infections. Indian population is vulnerable to infections of eye by virtue of subtropical climate, trauma and iatrogenic procedures. Infectious endophthalmitis is a threatening and potentially devastating intra- ocular infection caused by an array of organisms. Exogenous endophthalmitis is an infective complication of primary cataract, intraocular surgery and ocular trauma due to the introduction of infectious pathogens like bacteria and fungi, whereas the endogenous one is commonly due to systemic dissemination of the pathogens. To isolate and identify bacteria and fungi from various ocular specimens and to study antimicrobial resistance pattern of aerobic bacterial pathogens isolated. The present prospective study was carried out from July 2018 to August 2019 in the Department of Microbiology of Government Medical College, Amritsar. Vitreous humor samples received from the Department of Ophthalmology of Government Medical College, Amritsar were processed and bacterial and fungal isolates were identified using standard microbiological procedures. Antimicrobial susceptibility testing of bacterial isolates was performed as per the latest CLSI guidelines. Out of the 54 vitrous humor specimens processed $25(43.1 \%)$ were positive on culture. Amongst bacteria, Staphylococcus epidermidis $(36.8 \%)$ was the most predominant isolate, followed by Pseudomonas aeruginosa (26.3\%). Highest resistance was observed to fluoroquinolones followed by cephalosporins. No isolates showed resistance to Vancomycin or Imipenem. Amongst the fungi Aspergillus flavus $(62.5 \%)$ was the most common isolate followed by Candida albicans $(25 \%)$ cases. Mixed bacterial and fungal growth was obtained from 2 specimens. Our study highlights the importance of various etiological agents causig endophthalmitis with their antimicrobial resistance patterns. High prevalence of bacterial infections necessitates religious adherence to the standardised protocols can prevent and provide better treatment for this dreaded intraocular complication.
\end{abstract}

\section{Introduction}

Eye is a complex and sensitive organ and is therefore more vulnerable to trauma and various infections(1). Infectious endophthalmitis is a threatening and potentially devastating intra-ocular infection caused by an array of organisms(2). This clinical entity without early and timely intervention and appropriate therapy leads to rapid loss of vision and blindness. Despite various research and the best therapeutic efforts, even today the prognosis remains extremely variable. As endophthalmitis is not a single entity, but a heterogeneous group of infections with diverse aetiological agents, it is of foremost importance to establish a rapid, accurate diagnosis.

Inability to diagnose and treat endophthalmitis promptly amounts to neglect of the standard of care and this is grievous(3). Endophthalmitis is an inflammatory process that involves the ocular cavity and adjacent 
structures including the central cavity of the eye which is filled with vitreous fluid and surrounding tissues like the choroid and retina that are responsible for vision (4).

Exogenous endophthalmitis is an infective complication of primary cataract, intraocular surgery and ocular trauma due to the introduction of infectious pathogens like bacteria and fungi, whereas the endogenous one is commonly due to systemic dissemination of the pathogens (5).

Culture of intraocular specimens like vitreous humour, is still considered the gold standard in the diagnosis of endophthalimitis. Nevertheless, even under the most appropriate care traditional microbiological methods yield positive results in only $25-60 \%$ of the clinically diagnosed typical cases(6). The timely detection and appropriate management of this undesired ocular condition can possibly prevent irreversible vision loss. The empirical use of intra vitreal antibiotics have stood the test of time and have provided us with an efficacious management protocol of this acute ocular situation (7). The purpose of this study is to highlight the microbiological profile and associated clinical outcome in the eyes with culture positive exogenous endophthalmitis.

\section{Materials and Methods}

The present prospective study was carried out from July 2018 to August 2019 in the Department of Microbiology of Government Medical College, Amritsar. Vitreous humor samples were received from the Department of Ophthalmology of Government Medical College, Amritsar.

The samples were collected by the ophthalmologists in the operating theatre. For adults, ocular fluids were collected under local retrobulbar or peribulbar anesthesia and for children; it was collected under general anesthesia. This was done by insertion of a 22 to 27 gauge needle attached to a $1 \mathrm{ml}$ tuberculin syringe through the limbus or parsplana region into the cavity and aspiration of 0.1 to $0.3 \mathrm{ml}$ of undiluted vitreous humour.

\section{Transport of the specimen}

After the collection of the specimen, a sterile disposable needle was immediately fixed to the syringe containing the sample. The needle was then capped with a sterile rubber bung and placed in a sterile test tube container and was sent immediately to the laboratory, for microbiological analysis (8).

Specimens were subjected to direct microscopic examination i.e. gram staining, $10 \% \mathrm{KOH}$ wet mount, bacterial and fungal culture. Isolated bacteria \& fungi were identified by standard Microbiological procedures(9). Antimicrobial susceptibility testing of bacterial isolates was performed as per the latest CLSI guidelines(10).

\section{Results and Discussion}

Out of the 54 vitreous humor specimens processed 25(46.2\%) were positive on culture. Amongst 25 isolates, 17(68\%) bacterial isolates were obtained, 6(24\%) fungi were isolated while $2(8 \%)$ samples showed mixed growth of both bacterial and fungal isolates.

$\begin{aligned} & \text { Amongst bacteria, } \\ & \text { epidermidis }(36.8 \%) \text { was the most } \\ & \text { predominant isolate, followed by }\end{aligned}$
Pseudomonas aeruginosa $(26.3 \%)$ and
Streptococcus pneumoniae $(15.7 \%)$. Highest
resistance was observed to fluoroquinolones
followed by cephalosporins. No isolates
showed resistance to Vancomycin or
Imipenem. Amongst the fungi, Aspergillus
flavus $(62.5 \%)$ was the most common isolate
followed by Candida albicans $(25 \%)$ cases.


The present study represents detailed microbiological profile and antimicrobial susceptibility patterns of patients with endophthalmitis. The organisms causing this devastating infection vary according to the regions and climatic conditions all over the world hence making the findings of this study important. In India, fungi cause 10-20\% of post-operative endophthalmitis, while the dominance of bacteria is undoubted in west(11)(12). Fungal infection is associated with poorer prognosis and indolent course of the disease (13).

The culture positive rate of our study was $46.2 \%$ ( $n=54$ eyes) which is less as compared to other reports from India by Lalitha et al., (53\%) and Gupta et al., (52.5\%) (14). This can be attributed to the reason that, our institution being a tertiary care centre patients received intra vitreal antibiotics elsewhere, before presentation to us. This might have reduced the load of the viable microbes in the inoculums (15).

The bacteria isolated in post- operative endophthalmitis generally are same as that of same individual's oropharyngeal and mucosal flora (16). Gram-positive bacteria mainly coagulase-negative Staphylococcus (CoNS) are predominant $(65.64 \%)$ in acute variety of endophthalmitis.

The Staphylococcus aureus and Streptococcus viridians follow as $9.9 \%$ and $9 \%$, respectively (16). In contrast, our study showed $36.8 \%$ of CoNS and $15.7 \%$ of S. pneumoniae isolates out of the bacterial colonies which are considerably different from the literature.

The highlighting feature of our study was the isolation of large (26.3\%) number of Pseudomonas species out of the 19 bacterial isolates. This is in contrast to $11.53 \%$ as reported by a South Indian study (17). From our data it appears that vancomycin remains effective against Gram-positive bacteria \& Imepenem in Gram-negative bacteria in vitro and should remain the intra-vitreal drug of choice for antimicrobial therapy against these organisms. By contrast, ceftazidime and tobramycin as the first-line drugs, as advised by many ophthalmologists, should be reconsidered based on the present data.

Although Aspergillus endophthalmitis occurs most frequently from exogenous sources, our finding of this organism in 50\% of fungal cases warrants attention. However, reports of Aspergillus endophthalmitis were documented in the past in patients with immune compromised state, history of intravenous drug use and in those who had undergone intra-ocular surgery or had received presumably contaminated dextrose infusions (14) (18).

As observed over various studies, the common cause of organism entry into the eye is secondary to infected irrigating solutions, inadequately sterilised instruments and the operative environment. The isolation of Pseudomonas and Aspergillus species has been found to be significantly high in hot and humid climates.

Thus we believe that possible sources of contamination in our patients were in the operating theatre which could have possibly happened due to less stringent practices. Poor qualities of control measures in rural eye camp settings are often blamed for such contamination during surgery and postoperative care. Since most of our patients with post cataract endophthalmitis were operated in a hospital setting, there is a definite need for major improvement in surgical practices in hospitals in the developing countries. 
Table.1 Distribution of Culture positive isolates

\begin{tabular}{|c|c|c|c|c|c|}
\hline \multicolumn{3}{|c|}{ Bacterial Isolates } & \multicolumn{3}{|c|}{ Fungal Isolates } \\
\hline Organism & Number & $\%$ & Organism & Number & $\%$ \\
\hline $\begin{array}{l}\text { Staphylococcus } \\
\text { epidermidis }\end{array}$ & 7 & $36.8 \%$ & $\begin{array}{l}\text { Aspergillu } \\
\text { flavus }\end{array}$ & 3 & $37.5 \%$ \\
\hline $\begin{array}{l}\text { Streptococcus } \\
\text { pneumoniae }\end{array}$ & 3 & $15.7 \%$ & $\begin{array}{l}\text { Aspergillus } \\
\text { fumigatus }\end{array}$ & 2 & $25 \%$ \\
\hline $\begin{array}{l}\text { Pseudomonas } \\
\text { aeruginosa }\end{array}$ & 5 & $26.3 \%$ & $\begin{array}{l}\text { Candida } \\
\text { albicans }\end{array}$ & 2 & $25 \%$ \\
\hline $\begin{array}{l}\text { Klebsiella } \\
\text { spp. }\end{array}$ & 2 & $10.5 \%$ & Fusarium & 1 & $12.5 \%$ \\
\hline $\begin{array}{l}\text { Acinetobacter } \\
\text { spp. }\end{array}$ & 2 & $10.5 \%$ & - & - & - \\
\hline TOTAL & 19 & $100 \%$ & TOTAL & 8 & $100 \%$ \\
\hline
\end{tabular}

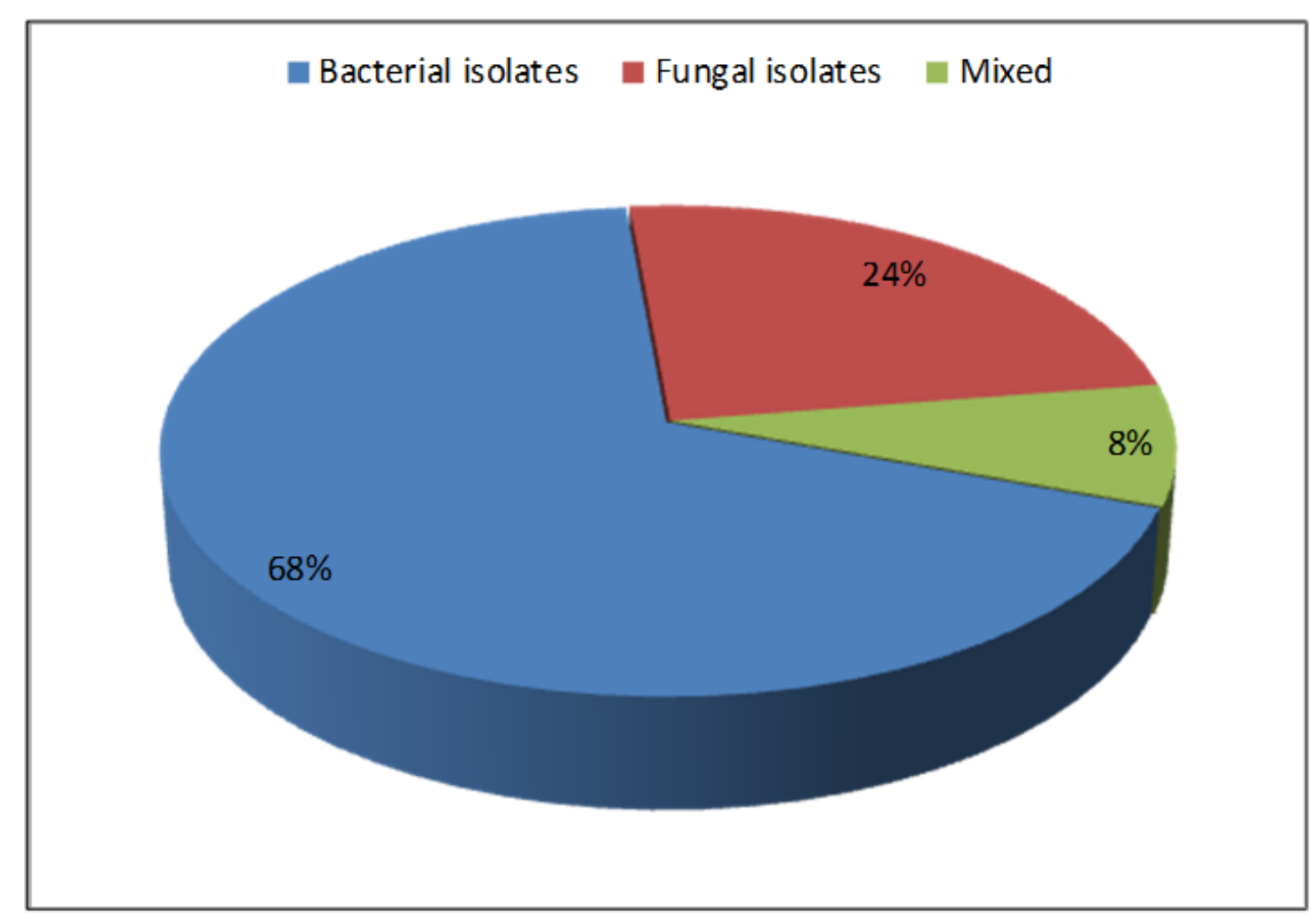

Fig.1 


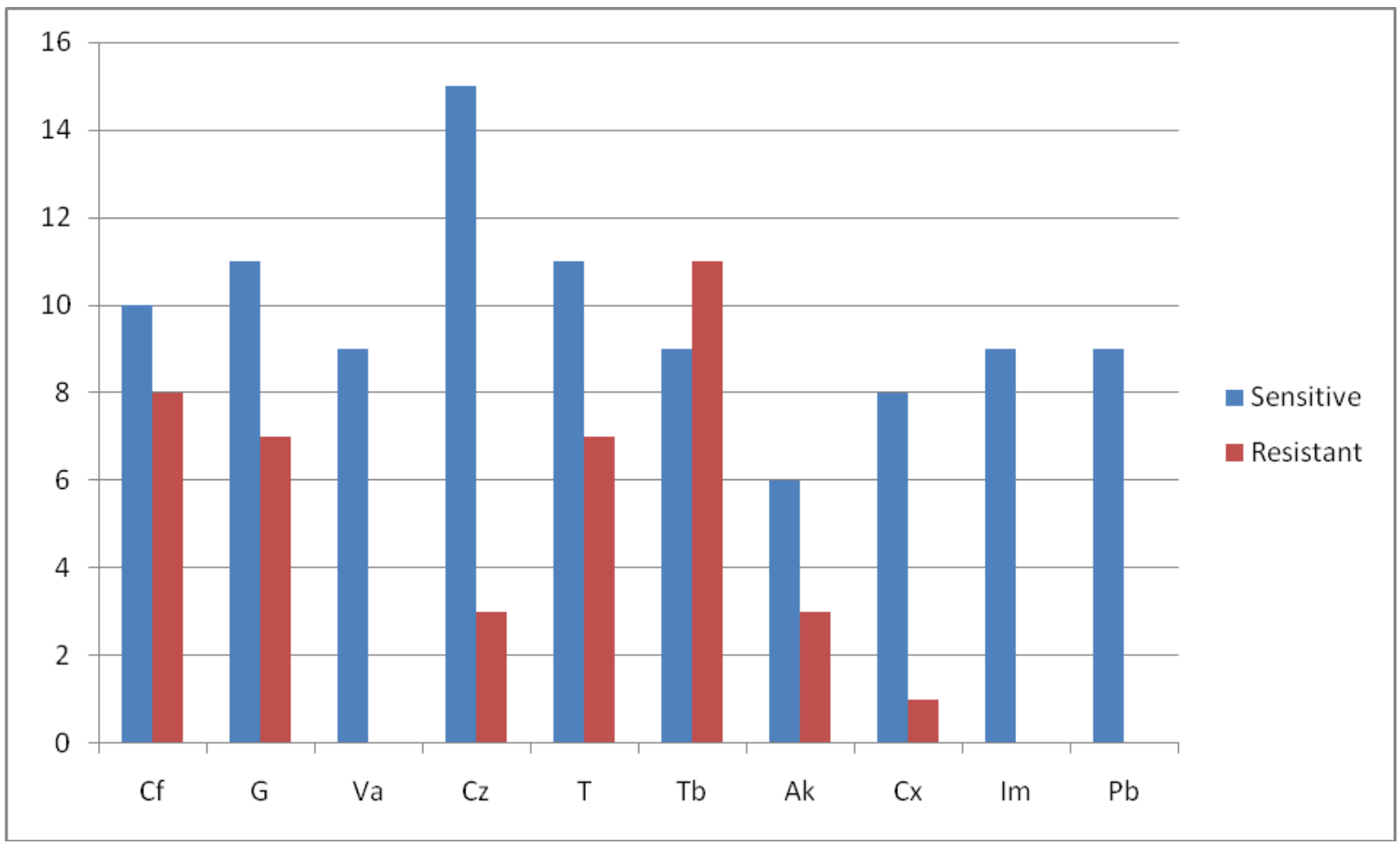

Fig.2 Antibiotic susceptibility testing pattern of bacterial isolates

The present study highlights the importance of various etiological agents causing endophthalmitis with their antimicrobial resistance patterns. High prevalence of bacterial infections necessitates strict adherence to the standardised protocols which can prevent and provide better treatment for this dreaded intraocular complication.

\section{References}

1. Bharathi $\mathrm{Mj}$, Amuthan $\mathrm{M}$, Viswanathan $\mathrm{S}$, Ramesh S, Ramakrishnan R. Prevalence of bacterial pathogens causing ocular infections in South India. Indian J Pathol Microbiol [Internet]. 2010 [cited 2020 Jan 18];53(2):281.

2. Bhattacharjee H, Bhattacharjee K, Gogoi K, Singh M, Singla B, Yadav A. Microbial profile of the vitreous aspirates in culture proven exogenous endophthalmitis: A 10-year retrospective study. Indian J Med Microbiol [Internet]. 2016 [cited 2020 Jan 18];34(2):153.

3. Khosravi AD, Mehdinejad M, Heidari M.
Bacteriological findings in patients with ocular infection and antibiotic susceptibility patterns of isolated pathogens. Singapore Med J [Internet]. 2007 Aug [cited 2020 Jan 19];48(8):7413.

4. YANOFF, M. Ocular Pathology. A Text Atlas. 1989;

5. Kernt M, Kampik A. Endophthalmitis: Pathogenesis, clinical presentation, management, and perspectives. Vol. 4, Clinical Ophthalmology. 2010. p. 121-35.

6. Sharma S. Ocular infections: Research in India. Indian J Med Microbiol [Internet]. 2010 [cited 2020 Jan 19];28(2):91.

7. Lemley CA, Han DP. Endophthalmitis: A review of current evaluation and management. Vol. 27, Retina. 2007. p. 662-80.

8. Anand AR, Therese KL, Madhavan HN. Spectrum of aetiological agents of postoperative endophthalmitis and antibiotic susceptibility of bacterial isolates. Indian J Ophthalmol [Internet]. 2000 Jun [cited 2020 Jan 19];48(2):123-8. 
9. Collee, J. G., Miles, R. S. and Wan B. Tests for the identification of bacteria, In: Mackie and Mc Cartney, Practical Medical Microbiology. Collee JG, Fraser AG MB\& SA, editor. Elsevier; 2014. 50$131 \mathrm{p}$.

10. Wayne PA. Performance standards for antimicrobial susceptibility testing. CLSI supplement M100. Clinical and Laboratory Standards Institute. 2019.

11. Taban M, Behrens A, Newcomb RL, Nobe MY, Saedi G, Sweet PM, et al., Acute endophthalmitis following cataract surgery: A systematic review of the literature. Vol. 123, Archives of Ophthalmology. 2005. p. 613-20.

12. Lalitha P, Rajagopalan J, Prakash K, Ramasamy K, Prajna NV, Srinivasan M. Postcataract endophthalmitis in South India: Incidence and outcome. Ophthalmology. 2005;112(11):1884-9.

13. Das T, Kunimoto D, Sharma S, Jalali S, Majji A, Nagaraja Rao $\mathrm{T}$, et al., Relationship between clinical presentation and visual outcome in postoperative and posttraumatic endophthalmitis in South Central India. Indian $\mathbf{J}$ Ophthalmol. 53(1):5.

14. Gupta A, Gupta V, Gupta A, Dogra MR, Pandav SS, Ray P, et al., Spectrum and clinical profile of post cataract surgery endophthalmitis in north India. Indian J Ophthalmol. 51(2):139-45.

15. Keynan Y, Finkelman Y, Lagacé-Wiens P. The microbiology of endophthalmitis: Global trends and a local perspective. Vol. 31, European Journal of Clinical Microbiology and Infectious Diseases. Springer-Verlag; 2012. p. 2879-86.

16. Mollan SP, Gao A, Lockwood A, Durrani OM, Butler L. Postcataract endophthalmitis: Incidence and microbial isolates in a United Kingdom region from 1996 through 2004. J Cataract Refract Surg [Internet]. 2007 Feb [cited 2020 Feb 11];33(2):265-8.

17. Madhavan H, Jambulingam $M$, Parameswaran S, Lysa S, Selvaraj M. A study on the incidence, microbiological analysis and investigations on the source of infection of postoperative infectious endophthalmitis in a tertiary care ophthalmic hospital: An 8-year study. Indian J Ophthalmol. 58(4):297.

18. Wykoff CC, Flynn HW, Miller D, Scott IU, Alfonso EC. Exogenous Fungal Endophthalmitis: Microbiology and Clinical Outcomes. Ophthalmology. 115(9):1501-7, 1507.e1-2.

\section{How to cite this article:}

Sukhjinder Singh, Loveena Oberoi, Karamjit Singh, Sapna Soneja and Anuradha Malhotra. 2020. Spectrum of Aetiological Agents of Endophthalmitis and Antimicrobial Resistance Pattern of Bacterial Isolates. Int.J.Curr.Microbiol.App.Sci. 9(07): 545-550. doi: https://doi.org/10.20546/ijcmas.2020.907.060 